\title{
RAND-36-Item Health Survey: A Comprehensive Test for Long-term Outcome and Health Status Following Surgery
}

\author{
IINA SAIMANEN ${ }^{1 *}$, VIIVI KUOSMANEN ${ }^{1 *}$, DINA RAHKOLA ${ }^{1 *}$, TUOMAS SELANDER ${ }^{2}$, \\ JARI KÄRKKÄINEN ${ }^{1}$, JUKKA HARJU ${ }^{3}$, SAMULI ASPINEN ${ }^{1 \#}$ and MATTI ESKELINEN ${ }^{1 \#}$ \\ ${ }^{1}$ Department of Surgery, Kuopio University Hospital and School of Medicine, \\ University of Eastern Finland, Kuopio, Finland; \\ ${ }^{2}$ Science Service Center, Kuopio University Hospital, Kuopio, Finland; \\ ${ }^{3}$ Abdominal Centre, Helsinki University Hospital, Helsinki, Finland
}

\begin{abstract}
Background/Aim: The aim of this study was to assess the 3-year health status of cholecystectomy patients by the RAND-36 Survey. Patients and Methods: Initially, 110 patients with symptomatic gallstone disease were randomized to undergo either minicholecystectomy $(M C)(n=58)$ or laparoscopic cholecystectomy $(L C)(n=52)$. RAND-36 survey was performed preoperatively, 4 weeks, 6 months and 3 years following surgery. Results: RAND-36 scores improved in several RAND-36 domains in MC and LC groups with a similar postoperative course over the 3-year study period. In addition, at the 3-year follow-up telephone interview, no significant differences in patient-reported outcome measures between $M C$ and LC patients were shown. The linear mixed effect model was used to test the overall significance of the RAND-36 survey during a 36-month follow-up period and the overall p-values were statistically significant in vitality, mental health (0.03), role physical and bodily pain domains. Conclusion: During the three years following cholecystectomy, four RAND-36 domains remained significantly higher, indicating a significant positive change in quality of life. RAND-36-Item Health Survey is a comprehensive test for analyzing long-term outcome and health status after cholecystectomy.
\end{abstract}

The classical outcome measures evaluated after surgery are usually perioperative course, complications, morbidity,

This article is freely accessible online.

*These Authors share first co-authorship. \#These Authors share last co-authorship

Correspondence to: Matti Eskelinen, MD, Ph.D., School of Medicine, University of Eastern Finland, P.O. Box 100, FI-70029 KYS, Finland. Tel: +358 17173311, Fax: +358 17172611, GSM: +358 400969444, e-mail: matti.eskelinen@kuh.fi

Key Words: RAND-36, long-term outcome, surgery, cholecystectomy. mortality and long-term outcome (post-operative symptoms, disease recurrence, long-term complications) (1-5). One of the most frequently used quality of life $(\mathrm{QoL})$ assessment tools for patients following surgery is the Short Form Health Survey Questionnaire (SF-36) (2, 6-13). RAND-36, much like SF-36, is a widely used generic, coherent, and comprehensive health survey. It contains a total of eight domains: general health $(\mathrm{GH})$, physical functioning (PF), mental health $(\mathrm{MH})$, social functioning (SF), vitality (VT), bodily pain (BP), role physical (RP) and role emotional (RE). RAND-36 includes the same set of items as SF-36, however, the scoring of GH and BP scales differs slightly $(14,15)$. Several studies have evaluated SF-36 in benign disease and in cancer patients following surgery (1, $2,4,8,10-12$ ). To our knowledge, RAND-36 is rarely evaluated in surgical patients $(3,16,17)$. In addition, RAND36-Item Health Survey has not been addressed earlier in minilaparotomy cholecystectomy (MC) versus laparoscopic cholecystectomy (LC) patients with ultrasonic dissection. Therefore, our study design was to investigate RAND-36 domains preoperatively and repeatedly following surgery. In addition, a 3-year follow-up structured telephone interview was conducted asking the patients if they had any symptoms or pain following surgery and the pain intensity was reported on an 11point numerical rating scale (NRS). The end-point of our study was to determine differences in the 3-year health outcome in MC versus LC patient groups.

\section{Patients and Methods}

The study was approved by the Ethics Committee of Kuopio University Hospital District, Kuopio, Finland (DNRO 27/02/2013), registered in the ClinicalTrials.gov database (ClinicalTrials.gov Identifier: NCT01723540, Consort diagram), and was conducted in accordance with the Declaration of Helsinki. Written consent was collected from participants, after receiving verbal and written information about the study. Operations were carried out in two hospitals in Finland; Helsinki University Central Hospital, Helsinki $(n=28)$ and Kuopio University Hospital, Kuopio $(n=82)$ between 
Table I. The clinical data of MC (minicholecystectomy) and LC (laparoscopy) patients. Data are mean (SD) or number of cases.

\begin{tabular}{lccc}
\hline Variable & $\begin{array}{c}\text { MC group } \\
\mathrm{n}=58\end{array}$ & $\begin{array}{c}\text { LC group } \\
\mathrm{n}=52\end{array}$ & $p$-Value \\
\hline Age & $50.1(13.6)$ & $52.1(13.4)$ & 0.46 \\
Gender (male/female) & $13 / 45$ & $17 / 35$ & 0.23 \\
Height $(\mathrm{cm})$ & $167.1(7.3)$ & $168.3(9.2)$ & 0.16 \\
Weight $(\mathrm{kg})$ & $77.4(14.2)$ & $82.0(18.0)$ & 0.48 \\
BMI $\left(\mathrm{kg} / \mathrm{m}^{2}\right)$ & $27.7(4.5)$ & $28.3(5.2)$ & 0.25 \\
Operative time (min) & $68.6(26.7)$ & $68.5(36.0)$ & 0.26 \\
Time at operative theater $(\mathrm{min})$ & $118.4(27.0)$ & $125.2(35.8)$ & 0.31 \\
Perioperative bleed $(\mathrm{ml})$ & $39.3(59.7)$ & $28.6(35.8)$ & 0.26 \\
ASA $1 / 2 / 3$ & $31 / 21 / 6$ & $21 / 20 / 11$ & 0.10 \\
Conversions & $2(3,5 \%)$ & $3(5,8 \%)$ & 0.58 \\
\hline
\end{tabular}

March 2013 and May 2015. The design of the study is presented in Figure 1.

The study was a prospective, randomized, multicenter clinical trial with two parallel groups. Altogether, 110 patients with uncomplicated symptomatic cholelithiasis confirmed by ultrasound were randomized to undergo cholecystectomy with LC, 52 patients, or with MC, 58 patients. Sealed envelope method was used for randomization. The operations were carried out by three consultantlevel surgeons (JH, PJ, ME), and both techniques were familiar to each operator.

The surgical techniques used were standardized in both groups (18). The LC is a laparoscopic operation and was performed using the four-trocar technique (two $10-\mathrm{mm}$ and two 5-mm trocars), and intra-abdominal pressure was set at $12 \mathrm{mmHg}$. Ultrasonic scissors (Harmonic ACE ${ }^{\circledR}$, Ethicon Endo-Surgery, Cincinnati, OH, USA) were used both in the MC and LC procedures.

The MC technique is a minimally invasive open technique with a very short wound. The rectus muscle is not cut, but split in the $\mathrm{MC}$ technique. A skin incision length of more than $7,0 \mathrm{~cm}$ or cutting of the rectus muscle was considered as a conversion to a conventional open operation. Incisions were infiltrated with local anesthetic $(20 \mathrm{ml}$ ropivacaine $7.5 \mathrm{mg} / \mathrm{ml})$ at the end of the operation.

RAND-36 was assessed pre- and postoperatively using the validated Finnish version of the questionnaire (15). Non-responders were interviewed by phone. The eight health domains were calculated from the 36 questions as instructed by the RAND-36 item health survey $(15,16)$. The RAND-36 questionnaire takes $10-$ $15 \mathrm{~min}$ to complete. We have earlier shown instructions for calculation of the eight health domains from the 36 questions of the RAND-36 survey (17).

At the 3-year follow-up, a telephone interview was conducted between January 2018 and May 2018. In the structured interview, the patients were asked whether they have experienced: a) similar abdominal symptoms or right upper quadrant pain, as they had before cholecystectomy, b) whether they have diarrhea or loose stools, and reflux symptoms, c) or if they had to avoid fatty or fried food to escape abdominal symptoms. If any of these symptoms were present, the interview continued with the question whether the patient had been further examined or received any other treatment for the residual symptoms. Pain or other symptoms at the incision area/port sites were filed, and patients reported the pain intensity on an 11-point numeric rating scale (NRS) when at rest, in physical activity, and lifting heavy objects or coughing. Regarding satisfaction with the surgery, the patients were asked whether the operation had had any impact on their QoL, if they were satisfied with the cosmetic outcome, and the satisfaction with the surgery in general. The patients were asked to answer the question on a fivepoint Likert-scale. The author (I.S.), who performed all interviews and filed the questionnaires of the study persons, did not participate in the primary operation or treatment of any of the study patients and was blinded to the operative technique used in cholecystectomy.

The data were entered and analyzed with a statistical software program (IBM SPSS Statistics 24.0, IBM, Armonk, NY, USA). Differences in the baseline characteristics between groups were tested by Fisher's exact test and in the case of continuous data the analysis was performed by independent samples $t$-test. Group differences at four time points were tested by the Mann-Whitney $U$ test and the Wilcoxon signed rank test. The linear mixed effect model was used to test overall significance of RAND-36 during the follow-period and the overall $\mathrm{p}$ value shows the interaction effects of different time and group interactions.

\section{Results}

Fifty-three patients $(53 / 58=91.4 \%)$ in the MC group and 44 $(44 / 52=84.6 \%)$ patients in the LC group underwent a followup phone interview at 36 months. Further on, $44(44 / 58=75.9$ $\%)$ of the MC patients and $43(43 / 52=82.7 \%)$ of the LC patients returned the 3-year RAND-36 questionnaire following surgery (mean $\pm \mathrm{SD}, 43.2 \pm 7.7$ months). The CONSORT diagram of the study and the perioperative surgical data are shown in Figure 1 and Table I, respectively.

Three patients in both groups (MC, 3/58 and LC, 3/53) had an incisional hernia of which two patients in both groups underwent hernia repair. None of the patients have shown signs of recurrent gallstones or surgery associated injuries in the bile ducts.

At the 3-year follow-up, no statistically significant differences in the structured interview domains between $\mathrm{MC}$ and LC patients were shown; residual abdominal symptoms $(p=0.26)$, right upper quadrant pain $(p=0.16)$, reflux symptoms $(p=0.13)$, diarrhea/loose stools $(p=0.27)$, fatty/fried food $(p=0.69)$, overall satisfaction with the procedure $(p=0.90)$, cosmetic satisfaction $(p=0.30)$, recommend the procedure to others $(p=0.60)$, quality of life $(p=0.34$, Table II).

The linear mixed effect model was used to test overall significance between groups during the 3-year follow-period and no significant differences were shown in any of the eight domains of RAND-36 at 4 weeks, 6 months or 36 months after surgery (Table III). The only significant difference between MC and LC groups following surgery was higher $\mathrm{BP}$ score in MC patients compared to LC patients at 6 months $(p=0.04$, Table III).

In the MC and LC groups combined (Table IV), the RAND-36 scores increased significantly in the 'VT' (mean 


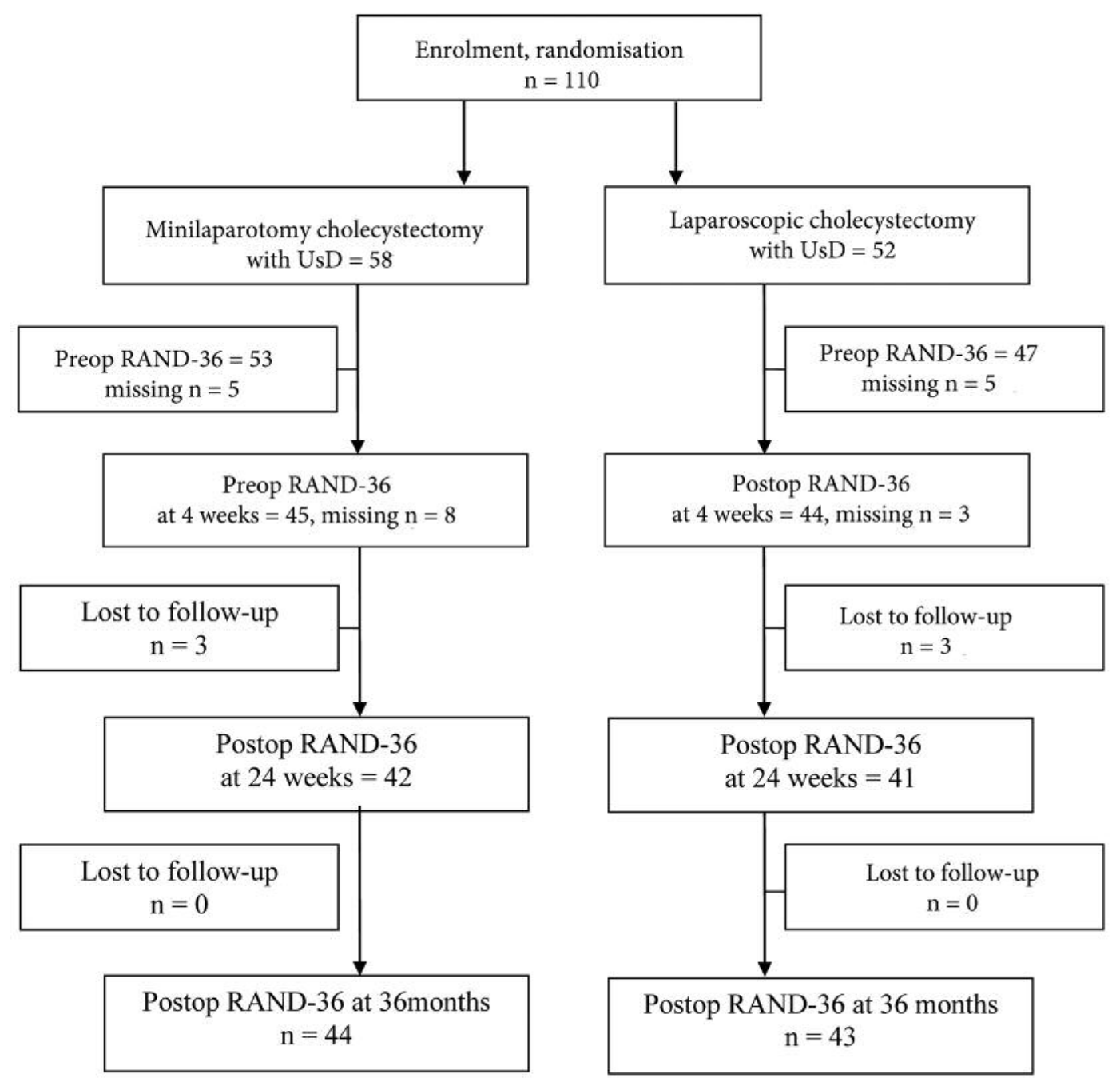

Figure 1. The flowchart of the study design.

preoperative score $65.0 \mathrm{vs}$. 4-week postoperative score 72.0, $p=0.03 v s .6$-month postoperative score 75.7, $p=0.001 v s$. 36-month postoperative score 72.3, $p=0.03$ ), ' $\mathrm{MH}$ ' (mean preoperative score $75.8 \mathrm{vs}$. 4-week postoperative score 85.2 , $p=0.001 v s .6$-month postoperative score 82.1, $p=0.04)$, 'RP' (preoperative score $69.3 \mathrm{vs}$. 4-week postoperative score 47.2, $p=0.008$ vs. 6 -month postoperative score $84.4, p=0.03$ ), 'BP' (mean preoperative score $57.6 \mathrm{vs}$. 6-month postoperative score 75.4, $p=0.0001$ vs. 36-month postoperative score 75.7, $p=0.0001$, Table IV). The linear mixed effect model showed overall significance of the RAND-36 during three years following cholecystectomy and the overall statistically significant RAND-36 domains were VT $(p=0.002), \mathrm{MH}$ $(p=0.031), \mathrm{RP}(p<0.001)$ and $\mathrm{BP}(p<0.001$, Table IV).

The 3-year postoperative scores of eight RAND-36 domains in MC and LC groups versus the Finnish reference scores are shown in Figure 2.

\section{Discussion}

The patient-reported outcome measures (PROMs) are important outcome indicators for evaluating treatment from a patient perspective $(1-5,19)$. In a review of 103 Swedish healthcare quality registries, authors encouraged to include PROMs in their arsenal of outcome measures and to collect PROM data to ensure highest level of registry classification (19). Evidencebased guidelines of the European Association for Endoscopic Surgery advice the use of the SF-36 for evaluating health status in patients following cholecystectomy, because the SF-36 questionnaire seems to be valid for evaluating patients' functional recovery after cholecystectomy (6). In our earlier preliminary RAND-36 report (16), there was no statistically significant difference between the LC and MC groups in seven RAND-36 domains, but the RE score was slightly higher in the LC group than in the MC group ( $p=0.038)$. 


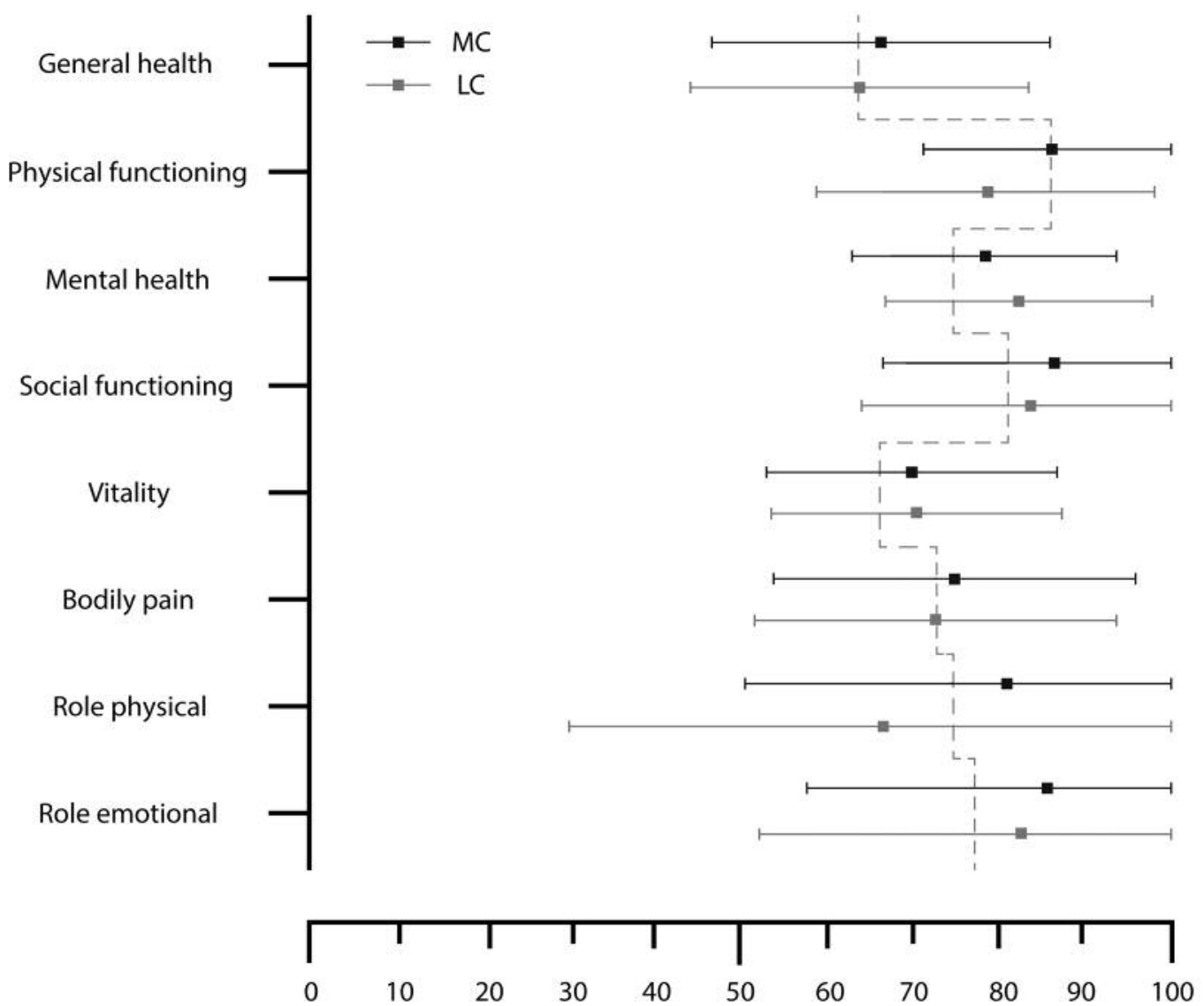

Figure 2. The 3-year postoperative scores of eight RAND-36 domains in MC and LC groups versus the age-and gender-adjusted Finnish reference scores (dashed line) (15).

Table II. The long-term symptomatic outcome and patient satisfaction at the 3-year follow-up structured interview of the MC (minicholecystectomy) and LC (laparoscopy) patients.

\begin{tabular}{|c|c|c|c|}
\hline Variable & $\begin{array}{c}\text { MC group } \\
n=53\end{array}$ & $\begin{array}{c}\text { LC group } \\
n=44\end{array}$ & $p$-Value \\
\hline \multicolumn{4}{|l|}{ Residual abdominal symptoms } \\
\hline Yes/no/could not say & $35.9 \% / 56.6 \% / 7.5 \%$ & $42.9 \% / 42.9 \% / 11.9 \%$ & 0.26 \\
\hline \multicolumn{4}{|l|}{ Right upper quadrant pain attacks } \\
\hline Yes/no/could not say & $5.7 \% / 94.3 \% /-$ & $4.8 \% / 95.2 \% /-$ & 0.16 \\
\hline \multicolumn{4}{|l|}{ Reflux symptoms } \\
\hline Less/not changed/more & $50.9 \% / 37.7 \% / 11.3 \%$ & $61.9 \% / 31.0 \% / 7.1 \%$ & 0.13 \\
\hline \multicolumn{4}{|l|}{ Diarrhea or loose stools } \\
\hline Less/not changed/more & $17.0 \% / 67.9 \% / 15.1 \%$ & $23.8 \% / 61.9 \% / 14.3 \%$ & 0.27 \\
\hline \multicolumn{4}{|l|}{ Avoid fatty/fried food } \\
\hline Yes/no/could not say & $37.7 \% / 60.6 \% / 1.9 \%$ & $38.1 \% / 54.8 \% / 7.1 \%$ & 0.69 \\
\hline \multicolumn{4}{|l|}{ Overall satisfaction with the procedure } \\
\hline Satisfied/dissatisfied/could not say & $88.7 \% / 7.8 \% / 3.8 \%$ & $95.2 \% / 4.8 \% /-$ & 0.90 \\
\hline \multicolumn{4}{|l|}{ Cosmetic satisfaction } \\
\hline Satisfied/dissatisfied/could not say & $81.1 \% / 17.0 \% / 1.9 \%$ & $90.5 \% / 7.2 \% / 2.4 \%$ & 0.30 \\
\hline \multicolumn{4}{|l|}{ Recommend the procedure to others } \\
\hline Yes/no/could not say & $77.4 \% / 7.5 \% / 15.1 \%$ & $85.7 \% / 7.6 \% / 7.1 \%$ & 0.60 \\
\hline \multicolumn{4}{|l|}{ Quality of life } \\
\hline Better/not changed/worse & $81.1 \% / 17.0 \% / 1.9 \%$ & $83.3 \% / 11.9 \% / 4.8 \%$ & 0.34 \\
\hline
\end{tabular}


Table III. The RAND-36 domains and scores in minicholecystectomy (MC) and laparoscopic cholecystectomy (LC) patients. Values are mean (standard deviation).

\begin{tabular}{|c|c|c|c|}
\hline RAND-36 & MC group & LC group & $p$-Value \\
\hline Physical functioning & & & $0.233^{*}$ \\
\hline Preoperative & $81.3(20.5)$ & $82.7(23.6)$ & 0.53 \\
\hline 4 weeks after surgery & $83.3(19.0)$ & $79.6(25.4)$ & 0.93 \\
\hline 6 months after surgery & $87.3(21.4)$ & $83.9(21.5)$ & 0.39 \\
\hline 36 months after surgery & $87.3(16.3)$ & $79.0(22.0)$ & 0.06 \\
\hline Social functioning & & & $0.254^{*}$ \\
\hline Preoperative & $77.9(21.8)$ & $76.5(19.3)$ & 0.21 \\
\hline 4 weeks after surgery & $76.9(21.1)$ & $77.6(23.0)$ & 0.76 \\
\hline 6 months after surgery & $88.0(20.0)$ & $84.4(22.0)$ & 0.42 \\
\hline 36 months after surgery & $87.5(19.2)$ & $84.3(19.2)$ & 0.32 \\
\hline Vitality & & & $0.729 *$ \\
\hline Preoperative & $64.0(18.5)$ & $64.2(19.9)$ & 0.98 \\
\hline 4 weeks after surgery & $68.9(18.3)$ & $66.6(23.8)$ & 0.97 \\
\hline 6 months after surgery & $74.2(17.8)$ & $72.3(17.5)$ & 0.50 \\
\hline 36 months after surgery & $70.0(17.2)$ & $71.0(18.8)$ & 0.67 \\
\hline Mental health & & & $0.572 *$ \\
\hline Preoperative & $76.6(15.1)$ & $83.0(21.1)$ & 0.63 \\
\hline 4 weeks after surgery & $82.5(14.5)$ & $80.9(15.7)$ & 0.74 \\
\hline 6 months after surgery & $82.2(15.5)$ & $80.6(17.0)$ & 0.61 \\
\hline 36 months after surgery & $79.6(16.5)$ & $81.3(13.0)$ & 0.87 \\
\hline Role physical & & & $0.107 *$ \\
\hline Preoperative & $65.3(38.1)$ & $67.9(36.4)$ & 0.74 \\
\hline 4 weeks after surgery & $39.7(38.2)$ & $48.0(42.1)$ & 0.36 \\
\hline 6 months after surgery & $81.5(33.6)$ & $81.6(33.8)$ & 0.93 \\
\hline 36 months after surgery & $81.1(33.4)$ & $67.7(41.1)$ & 0.12 \\
\hline Role emotional & & & $0.939 *$ \\
\hline Preoperative & $83.0(31.5)$ & $80.1(33.1)$ & 0.63 \\
\hline 4 weeks after surgery & $80.7(35.8)$ & $73.3(37.9)$ & 0.20 \\
\hline 6 months after surgery & $90.2(25.0)$ & $83.8(31.4)$ & 0.20 \\
\hline 36 months after surgery & $86.2(31.6)$ & $81.6(34.4)$ & 0.49 \\
\hline Bodily pain & & & $0.055^{*}$ \\
\hline Preoperative & $59.1(24.9)$ & $59.2(27.7)$ & 0.97 \\
\hline 4 weeks after surgery & $59.4(23.1)$ & $63.4(26.6)$ & 0.40 \\
\hline 6 months after surgery & $80.4(21.5)$ & $69.6(26.6)$ & 0.04 \\
\hline 36 months after surgery & $75.9(24.2)$ & $73.0(26.4)$ & 0.65 \\
\hline General health & & & $0.123^{*}$ \\
\hline Preoperative & $66.6(21.7)$ & $64.8(18.3)$ & 0.57 \\
\hline 4 weeks after surgery & $67.2(20.8)$ & $62.7(19.9)$ & 0.28 \\
\hline 6 months after surgery & $70.9(18.1)$ & $63.4(20.8)$ & 0.10 \\
\hline 36 months after surgery & $66.0(20.3)$ & $63.2(20.4)$ & 0.49 \\
\hline
\end{tabular}

*The linear mixed model $p$-value showing the interaction effects of different time and group interactions.

The results of the present study support the validity of the RAND-36 as a survey of health-related quality of life in cholecystectomy patients following surgery. In particular, BP, $\mathrm{RP}, \mathrm{MH}$ and VT scores improved significantly following cholecystectomy, which indicates that RAND-36-Item Health Survey could be a comprehensive test for long-term outcome and health-status. The present study cohort of patients was comparable to the Finnish reference population (15) in terms of the GH and BP scores 3 years following surgery. However,
Table IV. The RAND-36 domains and scores in minicholecystectomy $(M C)$ and laparoscopic cholecystectomy $(L C)$ groups combined. Values are mean (standard deviation).

\begin{tabular}{|c|c|c|}
\hline RAND-36 & $\mathrm{MC}$ and $\mathrm{LC}$ combined & $p$-Value \\
\hline Physical functioning & & $0.132 *$ \\
\hline Preoperative & $79.8(25.0)$ & \\
\hline 4 weeks after surgery & $81.3(23.4)$ & 0.965 \\
\hline 6 months after surgery & $86.4(21.6)$ & 0.05 \\
\hline 36 months after surgery & $85.4(19.3)$ & 0.175 \\
\hline Social functioning & & $0.254 *$ \\
\hline Preoperative & $79.4(22.5)$ & \\
\hline 4 weeks after surgery & $80.8(21.4)$ & 0.857 \\
\hline 6 months after surgery & $85.6(21.1)$ & 0.353 \\
\hline 36 months after surgery & $87.0(17.7)$ & 0.137 \\
\hline Vitality & & $0.002^{*}$ \\
\hline Preoperative & $65.0(19.4)$ & \\
\hline 4 weeks after surgery & $72.0(20.3)$ & 0.03 \\
\hline 6 months after surgery & $75.7(16.5)$ & 0.001 \\
\hline 36 months after surgery & $72.3(16.9)$ & 0.03 \\
\hline Mental health & & $0.031 *$ \\
\hline Preoperative & $75.8(18.2)$ & \\
\hline 4 weeks after surgery & $85.2(13.1)$ & 0.001 \\
\hline 6 months after surgery & $82.1(16.2)$ & 0.042 \\
\hline 36 months after surgery & $80.9(15.4)$ & 0.220 \\
\hline Role physical & & $<0.001 *$ \\
\hline Preoperative & $69.3(36.9)$ & \\
\hline 4 weeks after surgery & $47.2(38.5)$ & 0.008 \\
\hline 6 months after surgery & $84.4(29.1)$ & 0.030 \\
\hline 36 months after surgery & $75.5(37.2)$ & 0.631 \\
\hline Role emotional & & $0.725^{*}$ \\
\hline Preoperative & $78.3(33.9)$ & \\
\hline 4 weeks after surgery & $77.8(37.4)$ & 0.435 \\
\hline 6 months after surgery & $77.8(37.4)$ & 0.446 \\
\hline 36 months after surgery & $81.5(35.8)$ & 0.660 \\
\hline Bodily pain & & $<0.001 *$ \\
\hline Preoperative & $57.6(27.0)$ & \\
\hline 4 weeks after surgery & $63.1(24.1)$ & 0.775 \\
\hline 6 months after surgery & $75.4(25.4)$ & 0.0001 \\
\hline 36 months after surgery & $75.7(23.2)$ & 0.0001 \\
\hline General health & & $0.425^{*}$ \\
\hline Preoperative & $64.0(21.5)$ & \\
\hline 4 weeks after surgery & $66.8(20.9)$ & 0.922 \\
\hline 6 months after surgery & $66.9(21.6)$ & 0.894 \\
\hline 36 months after surgery & $65.3(22.0)$ & 0.941 \\
\hline
\end{tabular}

*The linear mixed model $p$-value showing the different time effects. A $p$-value in the preoperative versus 4 -week score and in the preoperative versus 6-month score and in the preoperative versus 36-month score.

the MH, SF, VT and RE scores, were higher compared to the reference population, and the bodily pain and the health change scores further increased by 6 months and 36 months following surgery, indicating recovery. Both MC and LC groups significantly improved the MH, SF, VT and RE scores at 36 months following surgery.

At the 3-year follow-up, no statistically significant differences in our structured telephone interview domains between MC and LC patients were shown; residual 
abdominal symptoms, right upper quadrant pain, reflux symptoms, diarrhea/loose stools, fatty/fried food, overall satisfaction with the procedure, cosmetic satisfaction, recommend the procedure to others and quality of life.

At the 3-year RAND-36 follow-up, the only statistically significant difference between MC and LC patients was higher BP score in MC group at 6 months following surgery. Moreover, the linear mixed effect model was used to test overall significance between groups during the 3-year follow-period and no significant differences were observed in any of the eight domains of RAND-36 at 4 weeks, 6 months or 36 months after surgery. Although, there are earlier reports available of SF-36 and RAND-36, the longterm outcome and health-status by RAND-36 in MC versus LC patients has been rarely reported. Marchiori et al. (3) evaluated the pelvic floor rehabilitation programme for continence recovery after radical prostatectomy by RAND36 -health survey and found that data provided by RAND36 questionnaire could help to evaluate the costs and benefits of treatment options. Pilger et al. (4) studied quality of life and sexuality of patients after treatment for gynaecological malignancies in 55 patients by the SF12 questionnaire and found that patients who reported changes of sexuality were also shown to have lower overall SF12 score. Yonemoto et al. (2) evaluated quality of life of long-term survivors of high-grade osteosarcoma by SF-36 and concluded that limbsparing surgery improved the quality of life of survivors, and the highest SF-36 domains were found to be GH, VT, SF and $\mathrm{MH}$. These results are in line with the results of this study.

In the MC and LC combined analysis, the RAND-36 scores increased significantly following surgery in the 'PF' (6 months), 'VT' (4 weeks, 6 months and 36 months), 'MH' (4 weeks, 6 months), 'RP' (4 weeks, 6 months), 'BP' (6/ months and 6 months) and 'health change' (4 weeks, 6/36 months). The linear mixed effect model was used to test overall significance of RAND-36 during the three-year follow-period and showed a statistically significant value of RAND-36 domains in vitality $(p=0.002)$, mental health $(p=0.031)$, score, role physical $(p<0.001)$ and bodily pain $(p<0.001)$.

In conclusion, RAND-36 scores improved significantly in several RAND-36 subscales in MC and LC groups with a similar postoperative course over the 3 -year study period. At the 3-year follow-up telephone interview, no statistically significant differences in patient-reported outcome measures between MC and LC patients were shown. It also seems that RAND-36-Item Health Survey is a comprehensive test for long-term outcome and health status after cholecystectomy. Health-related QoL is a multidimensional concept considering all aspects of patients' health and used widely as an outcome measure of treatment (1). Outcome data provided by QoL instruments complement clinical outcomes and may help to evaluate benefits of treatment options and care of patients.

\section{Conflicts of Interest}

The Authors report no conflicts of interest or financial ties to disclose. The Authors alone are responsible for the content and writing of this article.

\section{Authors' Contributions}

All Authors have met all of the following four criteria: 1 . Substantial contributions to the conception or design of the work or the acquisition, analysis, or interpretation of data for the work, 2. Drafting the work or revising it critically for important intellectual content, 3. Final approval of the version to be published, 4. Agreement to be accountable for all aspects of the work in ensuring that questions related to the accuracy or integrity of any part of the work are appropriately investigated and resolved.

\section{Acknowledgements}

The study was funded by the Heikki, Aino and Aarne Korhonen foundation and the EVO-funding of the Kuopio University Hospital, Finland.

\section{References}

1 Pallis AG and Mouzas IA: Instruments for quality of life assessment in patients with gastrointestinal cancer. Anticancer Res 24: 2117-2121, 2004. PMID: 15274411.

2 Yonemoto T, Ishii T, Takeuchi Y, Kimura K, Hagiwara Y, Iwata S and Tatezaki S: Evaluation of quality of life (QOL) in longterm survivors of high-grade osteosarcoma: a Japanese single center experience. Anticancer Res 27: 3621-3624, 2007. PMID: 17972526.

3 Marchiori D, Bertaccini A, Manferrari F, Ferri C and Martorana G: Pelvic floor rehabilitation for continence recovery after radical prostatectomy: role of a personal training re-educational program. Anticancer Res 30: 553-556, 2010. PMID: 20332469.

4 Pilger A, Richter R, Fotopoulou C, Beteta C, Klapp C and Sehouli J: Quality of life and sexuality of patients after treatment for gynaecological malignancies: results of a prospective study in 55 patients. Anticancer Res 32: 5045-5049, 2012. PMID: 23155277.

5 Schwameis K, Schwameis M, Zörner B, Lenglinger J, Asari R, Riegler FM and Schoppmann SF: Modern GERD treatment: feasibility of minimally invasive esophageal sphincter augmentation. Anticancer Res 34: 2341-2348, 2014. PMID: 24778041.

6 Korolija D1, Sauerland S, Wood-Dauphinée S, Abbou CC, Eypasch E, Caballero MG, Lumsden MA, Millat B, Monson JR, Nilsson G, Pointner R, Schwenk W, Shamiyeh A, Szold A, Targarona E, Ure B and Neugebauer E; European Association for Endoscopic Surgery: Evaluation of quality of life after laparoscopic surgery: evidence-based guidelines of the European Association for Endoscopic Surgery. Surgical Endoscopy 18: 879897, 2004. PMID: 15108103. DOI: 10.1007/s00464-003-9263-x

7 Keus F, de Vries J, Gooszen HG and van Laarhoven CJ: Laparoscopic versus small-incision cholecystectomy: Health status in a blind randomised trial. Surg Endosc 22: 1649-1659, 2008. PMID: 18071815, DOI: 10.1007/s00464-007-9675-0 
8 Meeus M, Nijs J, McGregor N, Meeusen R, De Schutter G, Truijen S, Frémont M, Van Hoof $\mathrm{E}$ and De Meirleir K: Unravelling intracellular immune dysfunctions in chronic fatigue syndrome: interactions between protein kinase R activity, RNase L cleavage and elastase activity, and their clinical relevance. In Vivo 22: 115-121, 2008. PMID: 18396793.

9 Keus F, Gooszen HG and van Laarhoven CJ: Systematic review: open, small-incision or laparoscopic cholecystectomy for symptomatic cholecystolithiasis. Aliment Pharmacol Ther 29: 359-378, 2009. PMID: 19035965. DOI: 10.1111/j.13652036.2008.03894.x

10 Kim JY1, Lee YH, Chong GO, Lee YS, Cho YL and Hong DG: comparative study between total laparoscopic and total robotic radical hysterectomy for cervical carcinoma: Clinical Study. Anticancer Res 35: 5015-5021, 2015. PMID: 26254401.

11 Gaedke IE, Wiebking U, O'Loughlin PF, Krettek C and Gaulke R: Clinical and Radiological Mid- to Long-term Outcomes Following Ankle Fusion. In Vivo 32: 1463-1471, 2018. PMID: 30348702. DOI: 10.21873 /invivo. 11400

12 Abe K, Yamamoto N, Hayashi K, Takeuchi A, Kato S, Miwa S, Igarashi K, Inatani H, Aoki YU, Higuchi T, Taniguchi Y and Tsuchiya H: Satisfaction after joint-preservation surgery in patients with musculoskeletal knee sarcoma based on various scores. Anticancer Res 39: 1959-1964, 2019. PMID: 30952739. DOI: 10.21873 /anticanres.13306

13 Kern JN, Weidemann F, O'Loughlin PF, Krettek C and Gaulke $\mathrm{R}$ : Mid- to long-term outcomes after split-thickness skin graft $v s$. skin extension by multiple incisions. In Vivo 33: 453-464, 2019. PMID: 30804125. DOI: 10.21873/invivo.11494

14 Hays RD and Morales LS: The RAND-36 measure of healthrelated quality of life. Ann Med 33: 350-357, 2001.

15 Aalto A-M, Aro AR and Teperi J: Rand-36 as a measure of health-related quality of life. Reliability, construct validity and reference values in the Finnish general population. Helsinki: National Research and Development Center for Welfare and Health (Research \#101 In Finnish, summary in English), 1999.
16 Harju J, Pääkkönen $M$ and Eskelinen M: Comparison of the quality of life after minilaparotomy cholecystectomy versus laparoscopic cholecystectomy: a prospective randomized study. Isr Med Assoc J 9: 147-148, 2007. PMID: 17402322.

17 Aspinen S, Kärkkäinen J, Harju J, Juvonen P, Kokki H and Eskelinen M: Improvement in the quality of life following cholecystectomy: a randomized multicenter study of health status (RAND-36) in patients with laparoscopic cholecystectomy versus minilaparotomy cholecystectomy. Qual Life Res 26: 665671, 2017. PMID: 28004321. DOI: 10.1007/s11136-016-1485-1

18 Harju J, Juvonen P, Kokki H, Remes V, Scheinin T and Eskelinen M: Minilaparotomy cholecystectomy with ultrasonic dissection versus laparoscopic cholecystectomy with electrosurgical energy: A randomized multicenter study. Scand J Gastroenterol 48: 1317-1323, 2013. PMID: 23971855. DOI: 10.3109/00365521.2013.822545

19 Orwelius L, Nilsson M, Nilsson E, Wenemark M, Walfridsson U, Lundström M, Taft C, Palaszewski B and Kristenson M: The Swedish RAND-36 Health Survey - reliability and responsiveness assessed in patient populations using Svensson's method for paired ordinal data. J Patient Rep Outcomes 2: 4, 2017. PMID: 29757320. DOI: 10.1186/s41687-018-0030-0
Received April 25, 2019

Revised May 14, 2019

Accepted May 15, 2019 